\title{
THE CHROMOSOME NUMBER OF GALACTITES DURIAEI SPACH (COMP.)
}

\author{
TH. W. J. GADELLA, E. KLIPHUIS and E. A. MENNEGA \\ Botanisch Museum en Herbarium, Utrecht
}

In a previous paper (GADELLA c.s. 1966) a list of chromosome numbers of flowering plants of S. France and Spain was published. Unfortunately, one of the plants was misidentified. Collection number 61, collected near Javea, Monte Mongo, Alicante (Spain), was incorrectly assigned to Cirsium acarna (L.) Moench. The plant was considered to be a Cirsium in view of the plumose pappus. The chromosome number of a number of plants grown from this seedsample turned out to be $2 n=22$, a number not found earlier in any Eurasiatic species of Cirsium.

MoOre \& Frankton (1963) studied several North American species of the genus Cirsium and pointed out that in the North American representatives of Cirsium the chromosome numbers $2 \mathrm{n}=34,32,30,28,26,24,22,20,18$ were present, whereas the Eurasiatic species exclusively show multiples of $\mathbf{n}=17$.

MoORe (in Löve 1967) reported the number $2 \mathrm{n}=32$ for Picnomon acarna Cass. (= Cirsium acarna (L.) Moench). Moore (in litt.) drew our attention to this discrepancy and supposed that some error might have occurred in the preparation of our paper. A reinvestigation of the chromosome number clearly indicated $2 n=22$ was correctly identified, but that the identification of the voucher material was wrong. Drs. Moore and FrankTon, after a careful examination of our voucher material, arrived at the conclusion that the plant from Javea belongs to the species Galactites duriaei Spach. LARSEN (1955) found the number $2 \mathrm{n}=22$ in another species of the genus Galactites : G. tomentosa Moench. The main difference between the genera Galactites and Cirsium is that in the former the anthers are connate, whereas in the latter they are free.

\section{ACKNOWLEDGEMENT}

The authors gratefully acknowledge the help of Drs. FrankTon and MoORE (Ottawa, Canada) in the solution of this problem.

\section{REFERENCES}

Gadella, Th. W. J., E. Kliphuis \& E. A. Mennega (1966): Chromosome numbers of some flowering plants of Spain and S. France. Acta Bot. Neerl. 15: 484-489.

LARSEN, K. (1955): Cytotaxonomical Studies on the Mediterranean Flora. Bot. Not. 108: 263-275.

MOORE, R. J. (1967): in Löve, IOPB Chromosome number reports IX. Taxon 16: 66.

-, \& C. Frankton (1963): Cytotaxonomic notes on some Cirsium species of the Western United States. Canad. Journ. Bot. 41: 1553-1567. 